\title{
Effects of Hot Strip Microstructure on the Deformation Microstructure and Textures after Cold Rolling in Ferritic Nonoriented Electrical Steels
}

\author{
A. Franke ${ }^{1, *}$, J. Schneider ${ }^{2}$, B. Bacroix ${ }^{3}$, and R. Kawalla ${ }^{2}$ \\ ${ }^{1}$ Stahlzentrum Freiberg e.V., Leipziger Straße 34, 09599 Freiberg, Germany \\ ${ }^{2}$ Institute of Metal Forming, Technische Universität Bergakademie Freiberg, Bernhard-von-Cotta-Str. 4, D- \\ 09596 Freiberg, Germany
}

${ }^{3}$ CNRS, Universite Paris 13 Nord

\begin{abstract}
The magnetic properties of electrical steels are related to the microstructure and texture of the final processed steel. There is an interplay and interaction of the microstructure and texture between the various processing steps. The ongoing structural changes at final annealing of the cold rolled material depend sensitively on the deformation structure after the cold rolling with high deformation. In this paper, we will study in detail the role of the microstructure of the hot strip on the deformation structure after cold rolling with high deformation.
\end{abstract}

Keywords: Ferritic FeSi, Hot rolling, Cold rolling, Deformation structure, Microstructure, Texture.

\section{INTRODUCTION}

The fabrication route of non-oriented electrical steels comprises casting, hot rolling, cold rolling and final annealing. A wide spectrum of non-oriented electrical steels is produced by variation of the content of $\mathrm{Si}$ and other additional elements as well by variation of the process parameter at the different processing steps. An additional processing step hot strip annealing before cold rolling is used to produce higher permeability grades commercially. Recently most attraction is paid to low magnetic loss materials, which are based on ferritic FeSi steels. These material grades with low values of the specific magnetic losses are widely used for electrical machines in hybrid and electrical cars.

The magnetic properties of electrical steels are related to the microstructure and texture of the final processed steel. There are not so many investigations available on the evolution of the microstructure and texture along the complete process starting from the hot strip fabrication for non-oriented ferritic steels [115]. This applies also to new technologies for hot strip fabrication like CSP and Thin Strip Casting [12-13]. Mostly the investigations regard only the effect of hot strip annealing with temperatures at $900^{\circ} \mathrm{C}$ or higher on the final annealing process. It was shown that the grain size of the hot rolled material plays an important role on

\footnotetext{
*Address correspondence to this author at the Stahlzentrum Freiberg e.V., Leipziger Straße 34, 09599 Freiberg, Germany;

Tel: 0049-3731 39 3100: E-mail: szf@iest.tu-freiberg.de
}

the stored energy after cold rolling and finally on recrystallization texture at final annealing after cold rolling [3-5]. This ideal complete recrystallized microstructure is quite different from those in a real fabrication process for hot band without hot band annealing, which exhibit a complex microstructure after hot rolling and result finally in inhomogeneous deformation substructures after cold rolling.

Regarding the process starting from the hot strip fabrication it is found that there is an interplay and interaction of the microstructure and texture between the various processing steps $[1,2,8,15]$. The ongoing structural changes at final annealing of the cold rolled material by recovery, recrystallization and finally grain growth depend sensitively on the deformation structure after the necessary cold rolling with high deformation. The cold rolling behavior itself is influenced by the microstructure of the hot strip.

In this paper, we will study in detail the role of the microstructure of the hot strip on the deformation structure after cold rolling with high deformation for FeSi 2.4. The regarded ferritic FeSi steel exhibits no phase transformation at hot rolling. To this purpose hot strips were fabricated with quite different processing parameters and were cold rolled with the same total reduction. Microstructure and texture of the different hot strip samples before cold rolling and after cold rolling were characterized by metallographic studies and electron backscatter diffraction (EBSD). The resulting features of the microstructure and texture are discussed. A deeper understanding of the interrelations between the microstructure of the hot strip and the cold 
rolled material may be a basic for further improvements of the technology and of the final obtained properties.

\section{EXPERIMENTAL}

The presented results concentrate on selected hot rolled samples of $\mathrm{FeSi} 2.4$ with a thickness of $2 \mathrm{~mm}$. The FeSi 2.4 alloy used for all the fabricated samples was a commercial alloy, which contains a certain amount of $\mathrm{Al}$ and $\mathrm{Mn}$. The alloy has a low content of $\mathrm{C}$ and other impurities. The FeSi 2.4 alloy was chosen as a typical example of ferritic FeSi steels for non-oriented electrical steels. These ferritic steels are favourable for non-oriented electrical steels with low values of the specific magnetic losses. Different hot rolled strips were prepared using the four stand pilot line for hot rolling at the Institute of Metal Forming, TU Bergakademie Freiberg (IMF). The pilot line enables to realize a reheating, a pre-hot rolling and a final hot rolling by four stands. The preheating temperature was above $1200^{\circ} \mathrm{C}$. The material used for hot rolling had a thickness of about $30 \mathrm{~mm}$. The regarded different samples were obtained by variation of the deformation per pass, especially at the last pass, the hot rolling finishing temperature as well as the conditions of coiling after finishing, respectively the temperature-time curve going from the temperature at the last pass to room temperature. Table 1 gives an overview of the samples, which are studied in this paper. The specific cooling conditions are given in any case in the table. Most of the samples were cooled quickly from the finishing temperature at hot rolling to $750^{\circ} \mathrm{C}$ and held at that temperature for a certain time. In some cases, the samples were rapidly quenched after the last pass at hot rolling: In addition, some of hot strip samples were annealed in a separate processing step before cold rolling. The annealing conditions are indicated in the Figures. The thermomechanical behavior for all the samples is determined by the flow curves and by the dynamic as well as static softening behavior for the regarded alloy composition. Cold rolling (CR) of the hot rolled strip with a thickness of $2 \mathrm{~mm}$ to a thickness of $0.5 \mathrm{~mm}$ was realized on a two-high stand at the IMF with four passes.

The microstructure before and after cold rolling was observed by optical microscopy. Microstructure of the hot strip as well as after cold rolling were also analyzed by the orientation imaging microscopy (OIM), the image quality as well as image quality plus rotation angle map (IQ plus misorientation), and the distribution function of the misorientation vs. angle obtained from EBSD measurements. The changes of the microstructure of the hot strip were described following the definition of recovery and recrystallization given in $[16,17]$. Straight recovery is characterized by the formation of subgrain structures with low angle grain boundaries, which leads to no change of the texture. Recrystallization comprises the appearance of nucleus and the formation of small grains. Appearance of large angle grain boundaries was characterized as recrystallization. The general microstructure of the hot strips can be classified in three types: equiaxed grains with different sizes, pancake grains and bands, see [18]. The resulting deformation substructures after cold rolling were classified following the classification in [19].

Texture is studied by the $\varphi_{2}=45^{\circ}$ section of the orientation distribution functions (ODFs) and by orientation imaging microscopy (OIM) obtained from EBSD measurements. Thereby a field emission scanning electron microscope (FESEM) of the type Zeiss Ultra 55 and software from AMETEK were used. Figure 1 shows the main fibers and components in the $\varphi_{2}=45^{\circ}$ section of the orientation distribution functions (ODFs), which we will particular view. To study the inhomogeneous nature of microstructure and texture

Table 1: Hot Rolled Samples Prepared at IMF of Ferritic FeSi Steels

\begin{tabular}{|c|c|c|c|c|}
\hline Sample & Thickness & HR: Starting Temperature & HR: Finishing Temperature & Annealing Temperature and Time at Cooling \\
\hline \hline 1 & $2 \mathrm{~mm}$ & $960^{\circ} \mathrm{C}$ & $820^{\circ} \mathrm{C}$ & Quenching to $400^{\circ} \mathrm{C}$ \\
\hline 2 & $2 \mathrm{~mm}$ & $1090^{\circ} \mathrm{C}$ & $860^{\circ} \mathrm{C}$ & $750^{\circ} \mathrm{C} / 20 \mathrm{~min}$ \\
\hline 3 & $2 \mathrm{~mm}$ & $1150^{\circ} \mathrm{C}$ & $770^{\circ} \mathrm{C}$ & Air Cooling to RT \\
\hline 4 & $2 \mathrm{~mm}$ & $1010^{\circ} \mathrm{C}$ & $930^{\circ} \mathrm{C}$ & $750^{\circ} \mathrm{C} / 75 \mathrm{~min}$ \\
\hline 5 & $2 \mathrm{~mm}$ & $1250^{\circ} \mathrm{C}$ & $1000^{\circ} \mathrm{C}$ & $750^{\circ} \mathrm{C} / 270 \mathrm{~min}$ \\
\hline 6 & $2 \mathrm{~mm}$ & $1010^{\circ} \mathrm{C}$ & $960^{\circ} \mathrm{C}$ & $750^{\circ} \mathrm{C} / 240 \mathrm{~min}$ \\
\hline $7^{* *}$ & $2 \mathrm{~mm}$ & $1150^{\circ} \mathrm{C}$ & $770^{\circ} \mathrm{C}$ & Air Cooling to RT \\
\hline $8^{* *}$ & $2 \mathrm{~mm}$ & $960^{\circ} \mathrm{C}$ & $820^{\circ} \mathrm{C}$ & Quenching to $400^{\circ} \mathrm{C}$ \\
\hline
\end{tabular}

${ }^{* *}$ Additional hot band annealing in a separate processing step before cold rolling: Sample $7-850^{\circ} \mathrm{C} / 20 \mathrm{~min}$; Sample $8-900^{\circ} \mathrm{C} / 2 \mathrm{~min}$. 
across the thickness we will analyze also certain areas within the samples.

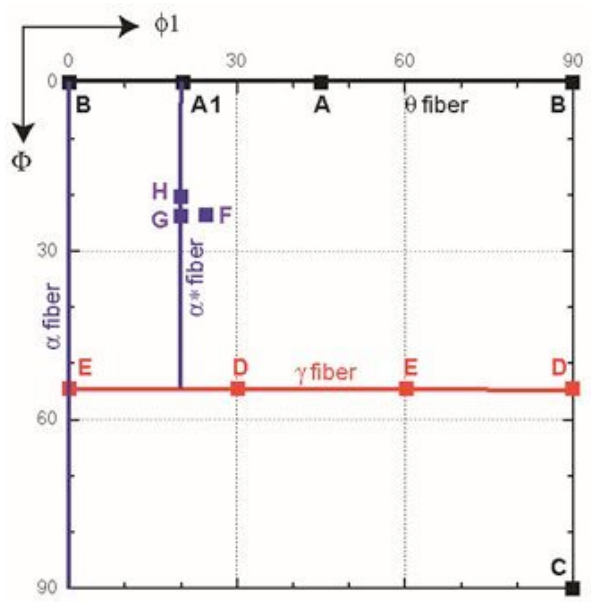

Figure 1: $\varphi_{2}=45^{\circ}$ section of ODF; $A=\{100\}<001>$ cube texture, $A_{1}=\{100\}<012>$,

$B=\{100\}<110>$ rotated cube texture, $C=$ $\{110\}<001>$ Goss texture, $D=$ component $\{111\}<112>$

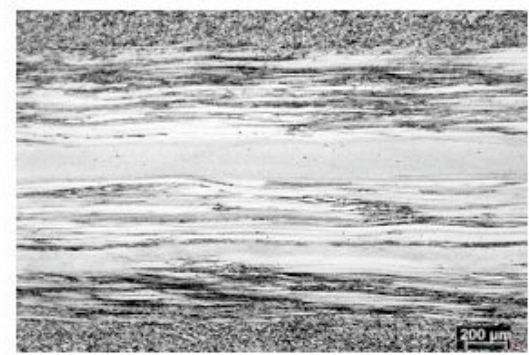

Sample 1

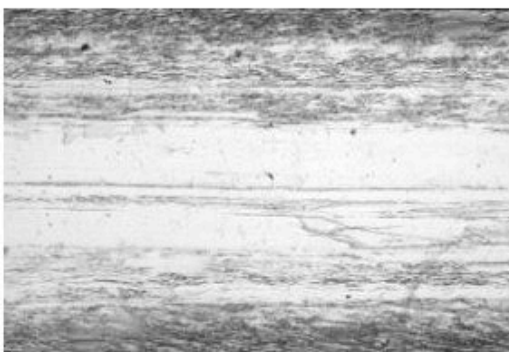

Sample 3

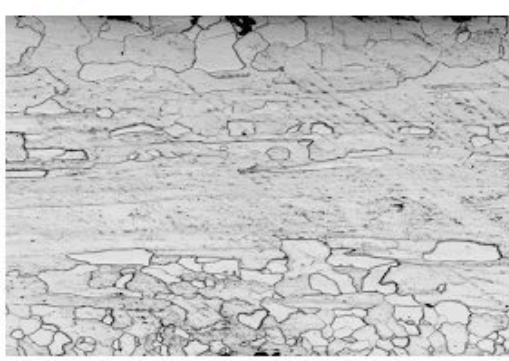

Sample 5 of the $y-$ fiber, $E=$ component $\{111\}<121>, \alpha^{*}$-fiber $\{\mathrm{h}, 1,1\}<1 / \mathrm{h}, 1,2>, \mathrm{F}=\{113\}<251>, \mathrm{G}=$ component $\{113\}<136>$ of the $\alpha^{*}$-fiber, $H=$ component $\{411\}<148>$ of the $\alpha$ - fiber, $F=\{113\}<251>, G=$ $\{113\}<136>, H=\{411\}<148>$,

\section{MICROSTRUCTURE OF THE HOT STRIP}

Figure 2 presents optical micrographs for the total cross section of samples 1 to 6 before cold rolling. The different finishing temperatures at hot rolling in connection with the different cooling, respectively annealing conditions (temperature - time curve) immediately after the last pass at hot rolling (samples $1,2,3,4,5,6)$ resulted in the varying appearance of the microstructure. One obtains recrystallized small grains at the surface of the hot rolled samples. Pancake grains (elongated grains) are observed in the region between the surface and the centre. Such elongated grains are sometimes nucleated inside of a

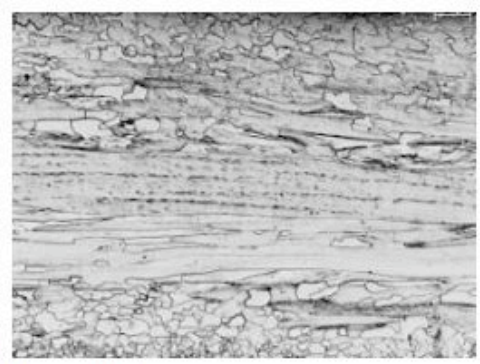

Sample 2

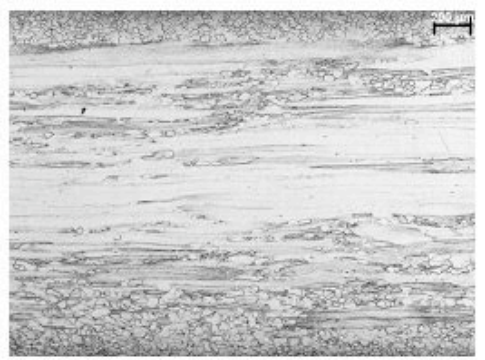

Sample 4

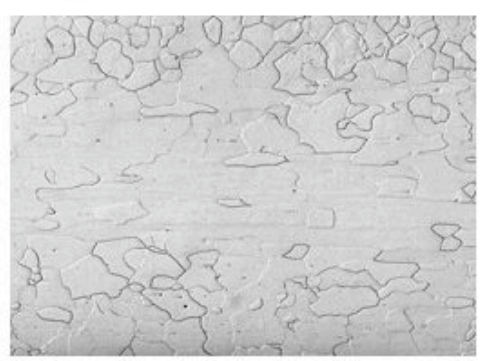

Sample 6

Figure 2: Optical micrograph for the total cross section of samples 1 to 6 before cold rolling; thickness before CR 2.00 mm; size scale is like in Figure 3. 
deformation band. Over a large region near the centre one has mostly deformation bands.

A quite different image is obtained for the hot rolled samples (samples 7 and 8 ), which were annealed in a separate step before cold rolling as can be seen from Figure 3. A recrystallized grain structure with a rather inhomogeneous grain size is obtained for sample 7 , while the recrystallization is incomplete across the thickness for sample 8 . To reach a more homogeneous recrystallized microstructure a rather high annealing temperatures above $900^{\circ} \mathrm{C}$ is necessary, see also $[5$, 20].

The variety of the process parameters to fabricate hot rolled strips results in quite different microstructure. Nevertheless, the resulting microstructure may be roughly classified as follows. Mostly, an inhomogeneous microstructure across the thickness results, which is characterized by small grains in the surface area and deformation bands in the central region. Sometimes more or less elongated grains appear in the central region. At rapid cooling after the last pass at hot rolling deformation bands are obtained more or less across the whole thickness. All these observations indicate clearly that the development of the microstructure is driven by the stored deformation energy at hot rolling and the thermal energy at coiling, respectively the temperature -time curve after the last pass. The static softening after hot rolling is the dominant process. A complete recrystallized microstructure is only obtained after an additional hot strip annealing in a separate processing step before cold rolling.

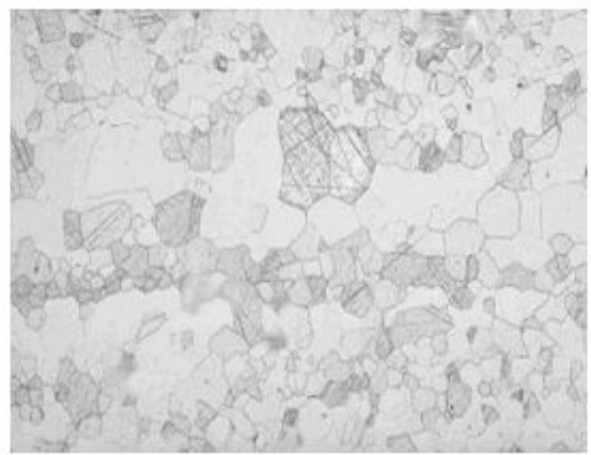

Sample 7
The image of the microstructure at varying process parameters at hot rolling for other ferritic FeSi steels, like FeSi3.0, is the same, see [11]. The resulting variety of the microstructure and texture of the fabricated hot strips by the pilot-line at the IMF in Freiberg is quite similar to the microstructure and texture of commercial hot strip samples at similar process conditions (rolling temperatures, cooling conditions), see for instance Figure 15 in [21].

The resulting crystallographic texture is also determined by the thermomechanical parameters at hot rolling. Figure 4 exhibit the $\varphi_{2}=45^{\circ}$ section of ODF for the whole cross section for the samples $1,2,3$ and 7 . For sample 1 (rapidly quenched after the last pass at hot rolling) a strong $\alpha$ - fiber texture, a remarkable cube fiber texture and a certain intensity of the $\mathrm{y}$ - fiber components were obtained. Samples 2 exhibit a high intensity of cube fiber texture and some $\alpha$ - fiber texture. Sample 2 were annealed immediately after the last pass at hot rolling. For sample 2 the intensity of the $\alpha$ fiber texture is much lower compared to sample 3 . The texture image of sample 3 is like to sample 1 due to the similar cooling conditions after the last pass at hot rolling.

These observed features in the $\varphi_{2}=45^{\circ}$ section of ODF differ to the characteristic of ferritic low C-steels and IF steels and also of FeSi3.0 as described in [22].

An additional hot strip annealing in a separate processing step before cold rolling, see sample 7 in Figure 4, resulted in a high cube fiber texture. Still the intensity of $\alpha$ - fiber texture is high. Such a high intensity of cube fiber texture is not obtained for a hot strip annealing, which do not give a complete recrystallized

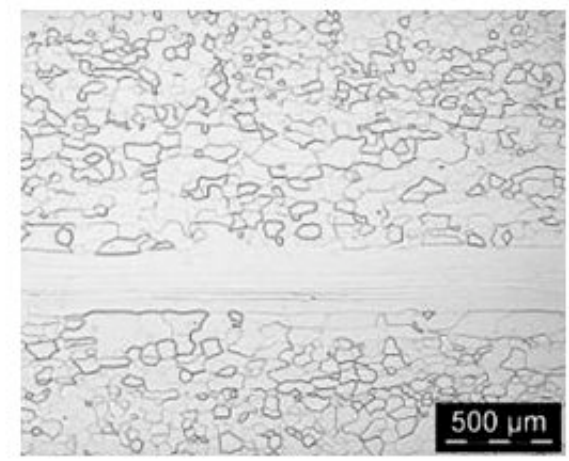

Sample 8

Figure 3: Optical micrograph for the total cross section of samples 7 and 8, which appeared a hot strip annealing in a separate processing step before cold rolling; size scale is the same (Sample $7-850^{\circ} \mathrm{C} / 20 \mathrm{~min}$; Sample $8-900^{\circ} \mathrm{C} / 2 \mathrm{~min}$ ). 


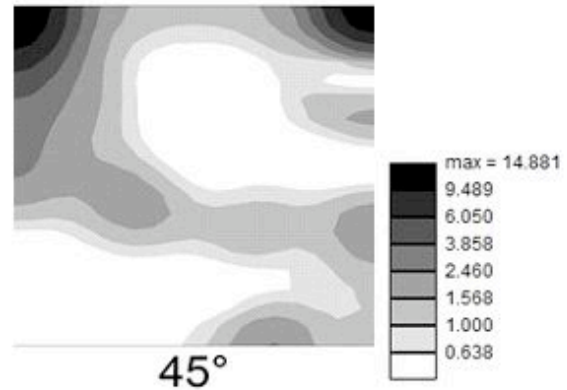

Sample 1

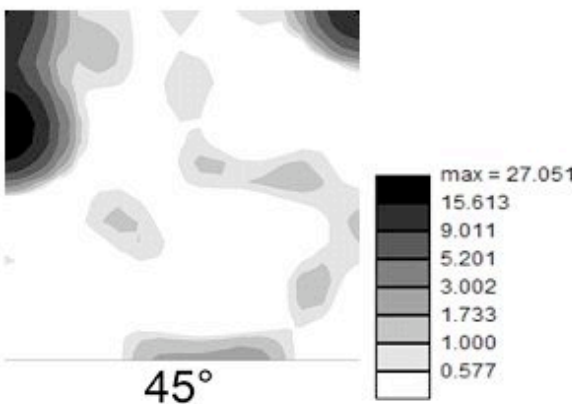

Sample 3

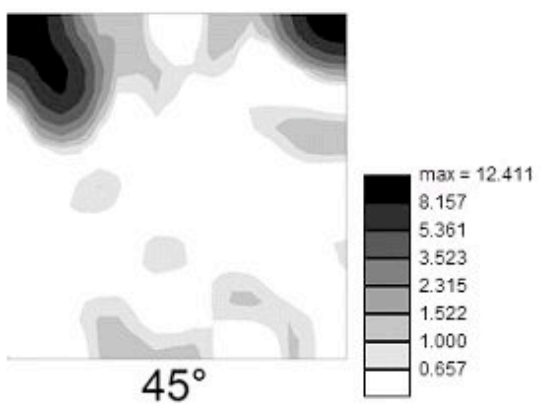

Sample 2

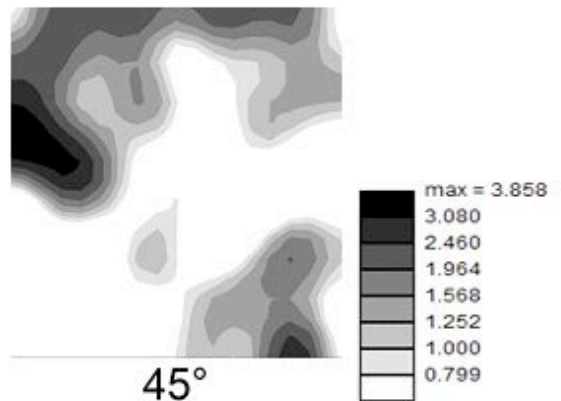

Sample 7

Figure 4: $\varphi_{2}=45^{\circ}$ section of ODF for the whole cross section for the samples 1, 2, 3 and 7 before cold rolling.

grain structure across the thickness, see Figure $\mathbf{5}$ (sample 8). The microstructure of the sample 8 is given in Figure 3. The appearance of texture for the hot strip before cold rolling depends sensitively on the hot rolling conditions and the process after the last pass as well as on the conditions of the optional hot strip annealing in a separate processing step before cold rolling.

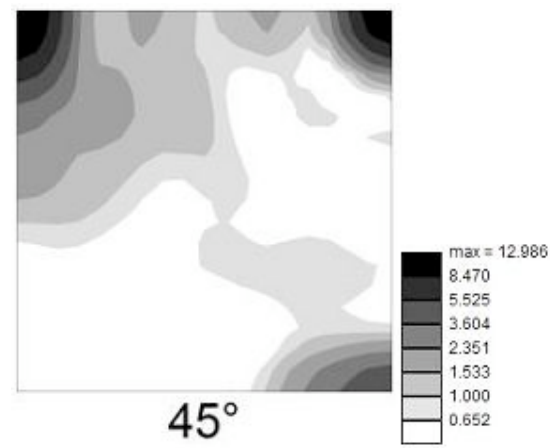

Figure 5: $\varphi_{2}=45^{\circ}$ section of ODF for the whole cross section of sample 8 after hot strip annealing, see also [11].

The inhomogeneous character of the texture across the thickness in connection with the inhomogeneous microstructure due to quite different softening processes for the different hot strips across the thickness can be clearly seen in the following Figures.
Figure 6 and 7 gives the OIM for sample 1 and sample 2 , respectively for sample 7 and sample 8 . The texture components, which are indicated by OIM are more explained in Figure 8. In the OIM the notation 111, 001, 101 are connected with the crystal reference system. Thereby we have blue -111 parallel ND (gamma fiber); and red - 100 parallel ND (cube fiber). ND gives the normal direction of the sample. These Figures demonstrate that the softening processes (recovery, recrystallization and grain growth) takes place rather inhomogeneous across the thickness for the regarded samples. For the samples 1 and 2, which were treated in a different way after the last pass at hot rolling, we observe a quite different behavior.

For the sample 1 , which was rapidly quenched after the last pass at hot rolling, we see a mixture: bands with $\mathrm{y}$ - fiber texture $(<111>$ parallel ND) and bands with cube fiber texture texture $(<001>$ parallel ND). For sample 2 we have in the central part mainly bands with cube fiber texture $(<001>$ parallel ND) and bands with a texture nearby the cube fiber texture $(<001>$ parallel ND). We observed no bands with $y$ - fiber texture $(<111>$ parallel ND) in the center. In the region at the surface, a recrystallized structure is found for sample 1 and 2. The different image for sample 1 and 2 may 

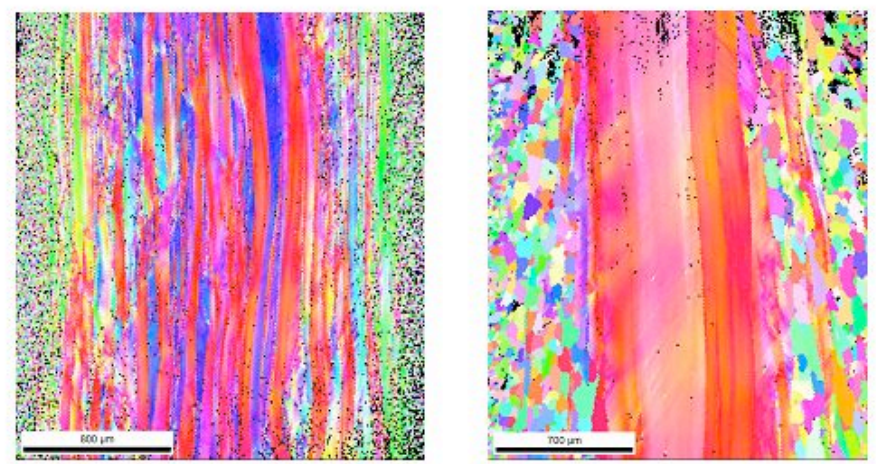

Sample 1

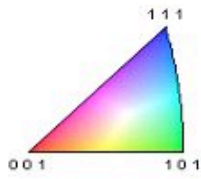

Sample 2

Figure 6: Orientation Imaging Microscopy (OIM) map of sample 1 and sample 2.

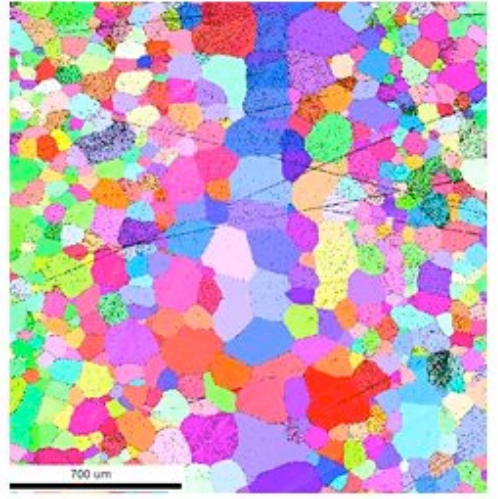

Sample 7

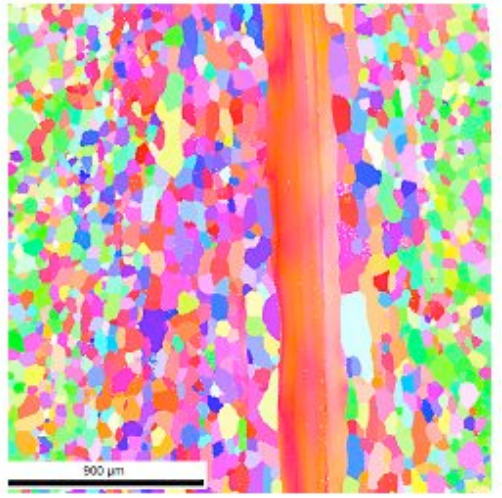

Sample 8

Figure 7: Orientation Imaging Microscopy (OIM) map of sample 7 and sample 8.

indicate that we have a quite different deformation state for our hot rolled samples with a thickness of $2 \mathrm{~mm}$ in the central part. For sample 7, which suffer an additional hot strip annealing in a separate processing step, we get a fully recrystallized state. We see mainly grains with $\gamma$ - fiber texture in the region near the center. If the additional hot strip annealing in a separate processing step before cold rolling is not realized under optimum conditions, see sample 8 in Figure 7 , the central part is still deformed.

For the regarded non-oriented electrical steels a high intensity of the preferable magnetic texture components, respectively fibers, which comprise, cube fiber texture and $\alpha^{*}$ fiber texture, are desirable for the fully processed material (high permeability grades). It should be mentioned that a high intensity of $\alpha$ - fiber texture as well as $\mathrm{Y}-$ fiber texture is undesirable in the finally processed material. Even a high density of Goss texture in not convenient for non-oriented electrical steels. To reach such a preferable texture in the fully processed material the hot strip should already exhibit a higher intensity of cube fiber texture and a lower intensity of $\alpha$ - fiber texture as well as $\gamma-$ fiber texture. This makes a clear difference to the conventional steels and has to be taken into account.

Generally, a rather different image for the microstructure and texture across the thickness is obtained for the hot strip before cold rolling. It depends sensitively on the processing parameters (deformation at the passes at hot rolling, starting and finishing temperature at hot rolling, thermal treatment after the last pass or rapid cooling, additional hot band annealing). This should be reflected in the microstructure and texture after cold rolling. 


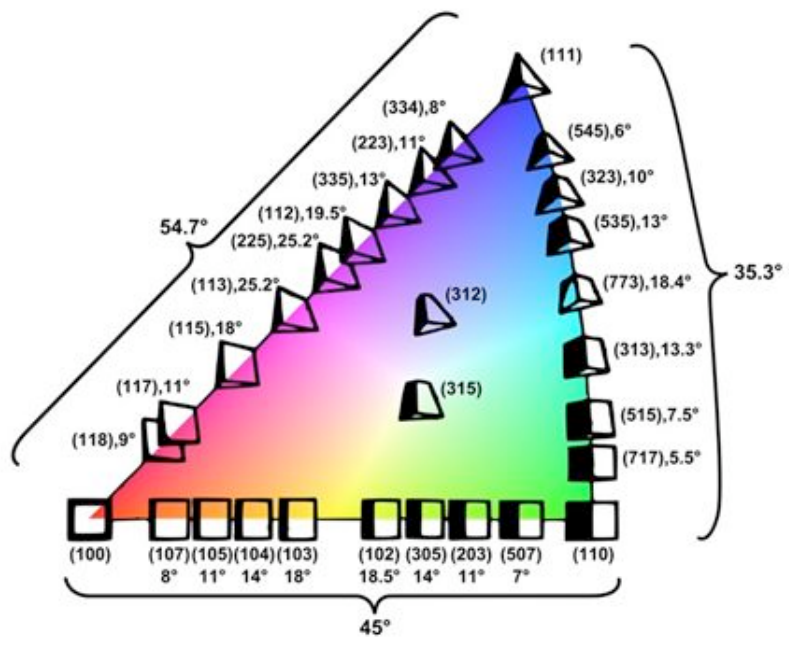

Figure 8: Texture components described by OIM (from literature).

\section{DEFORMATION STRUCTURE AFTER COLD ROLLING}

The resulting complexity of the microstructure at cold rolling with high deformation of the hot strips with a thickness of $2 \mathrm{~mm}$ to a final thickness of $0.50 \mathrm{~mm}$ is demonstrated by optical micrographs in Figure 9.
Shear bands are clearly visible in the optical micrographs for samples 2 and 7. Sample 2 was thermal treated in an appropriate way immediately after the last pass at hot rolling. Sample 7 was thermal annealed in a separate processing step before cold rolling. Shear bands are described as highly effective sites for nucleation of recrystallization [19]. Figure 10 and 11 present the OIM for the samples 1 and 2, respectively the samples 3 and 7 . The OIM in Figures 10 and 11 indicate the presence of bands with $\gamma$ - fiber texture ( $<111>$ parallel NR) as well as bands with cube fiber texture $(<001>$ parallel ND) more or less over the thickness. Thereby the portion of the area with $\mathrm{y}$ - fiber texture seems to be larger for the sample with an additional hot strip annealing before cold rolling (sample 7). Shear bands are visible in the areas with $\mathrm{Y}$ fiber texture ( $<111>$ parallel NR).

Figures 12 to 14 exhibit the inhomogeneity of the microstructure and texture across the thickness of areas after cold rolling. One finds a rather complex figure. Figure 12 shows the $I Q$, the distribution function of misorientation vs. angle, the OIM and the $\varphi_{2}=45^{\circ}$ section of the ODF for a band with mainly cube fiber texture (selected area of sample 2, see Figure 10).

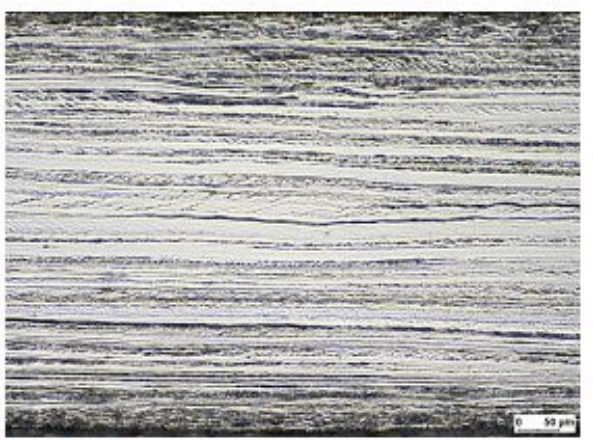

Sample 1

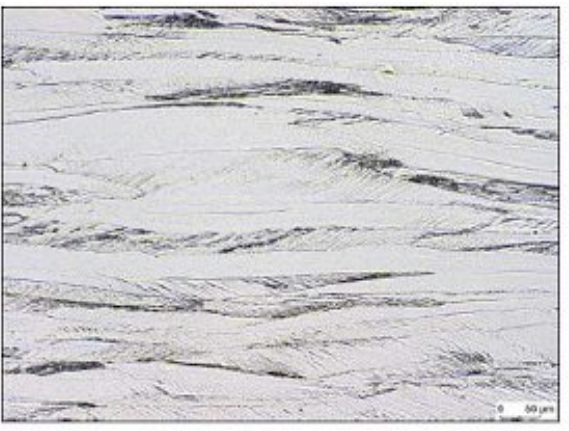

Sample 2

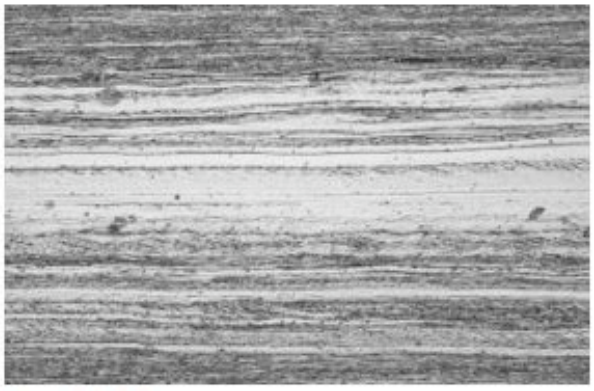

Sample 3

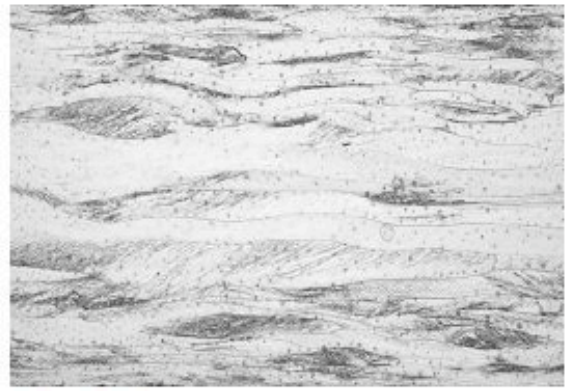

Sample 7

Figure 9: Optical micrograph for total cross section of samples 1, 2, 3 and 7 after cold rolling (CR); thickness after CR 0.50 $\mathrm{mm}$. 
High intensity of small angles in the distribution function of the misorientation as well as a high quality of the EBSD pattern is typical for such a deformation band.

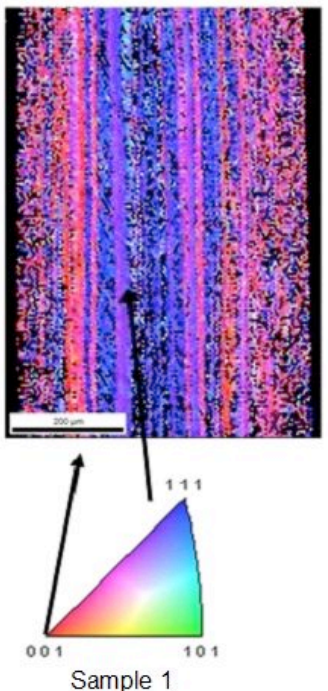

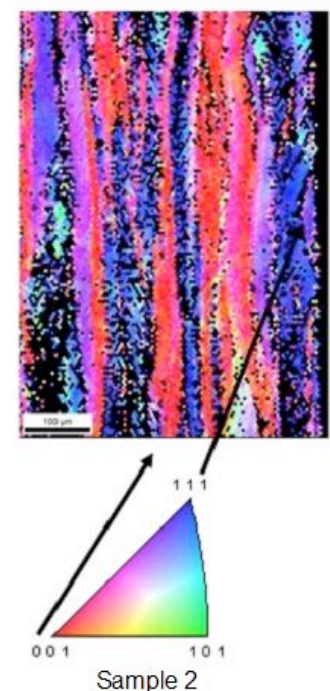

Figure 10: OIM map of sample 1 and 2.

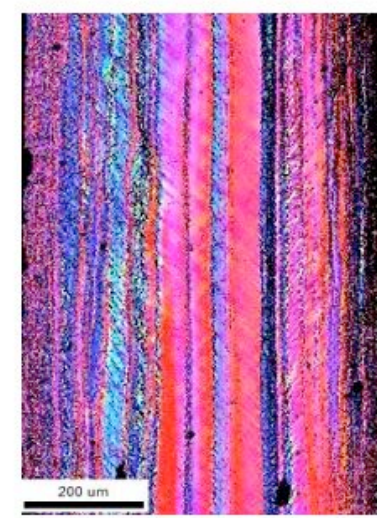

Sample 3

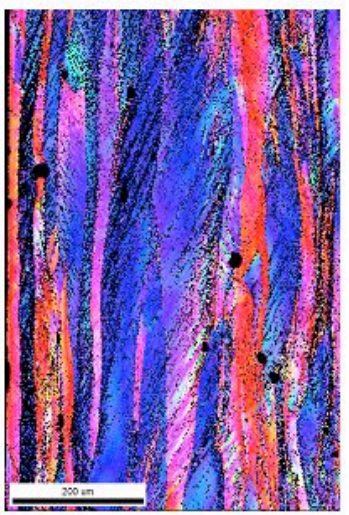

Sample 7
Figure 11: OIM map of sample 3 and 7.

Figure 13 gives the $I Q$, the distribution function of misorientation vs. angle, the OIM and the $\varphi_{2}=45^{\circ}$ section of the ODF for a band with mainly $Y$ - fiber texture of sample 7 . Figure 14 presents the IQ, the OIM and the $\varphi_{2}=45^{\circ}$ section of the ODF for another area of sample 7 with $Y$ - fiber texture, which contains shear bands. A low EBSD pattern quality is taken as an indicator for a shear band. Figure $\mathbf{1 5}$ demonstrates the complexity of the "local deformation substructure". It gives the IQ, the distribution function of misorientation vs. angle, the OIM and the $\varphi_{2}=45^{\circ}$ section of the ODF after cold rolling for a "transition area" between bands with mainly cube fiber texture near the center of sample 2. There is no unique microstructure and texture for the regarded area. Sheared microbands are visible. In
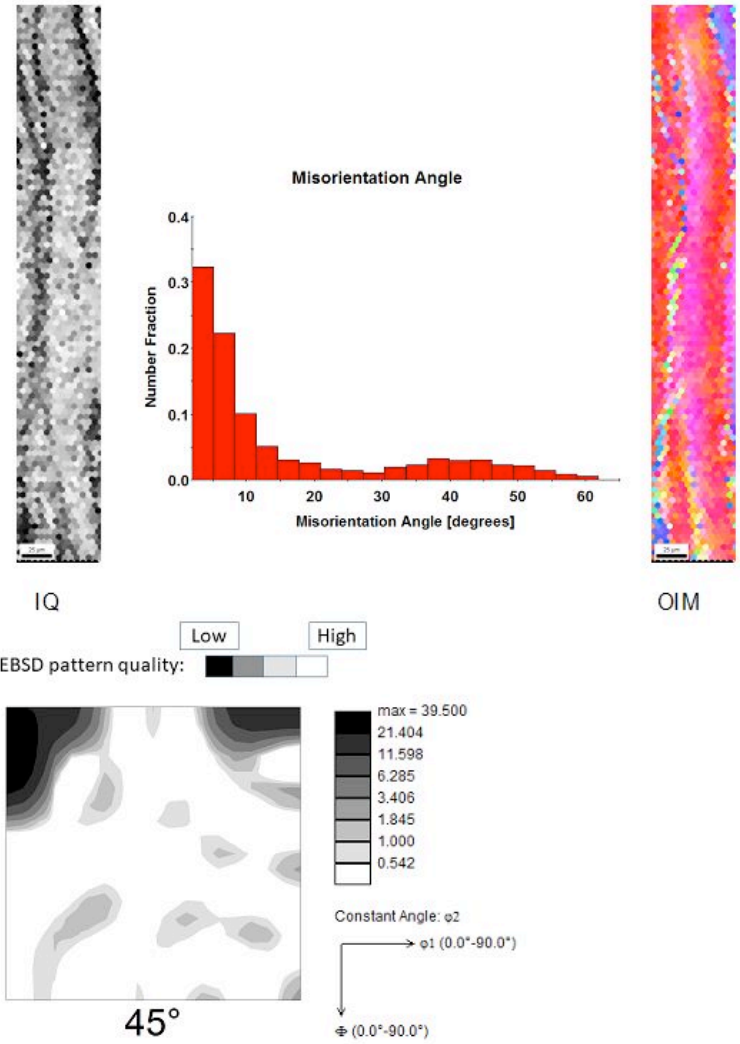

OIM
Figure 12: $I Q$, distribution function of misorientation vs. angle, OIM and $\varphi_{2}=45^{\circ}$ section of the orientation distribution function for a band with mainly cube fiber texture (selected area of sample 2, see Figure 10) after cold rolling.

addition, recrystallization, which comprises the appearance of nucleus and the formation of small grains (nucleus), took place already in certain regions. This recrystallized area exhibit intense cube fiber texture and $\alpha^{*}$ - texture, see Figure 15 (ODF for A). On the other hand the sheared "microbands" have a quite different texture, see Figure 15 (ODF for B). The texture is nearby 111 parallel ND.

In summary, areas with a wide spread of texture components, larger intensity of high angle misorientation beside low angle misorientation as well as a mixture of high image quality and low image quality are found for samples 2 and 7 in the central region. The larger intensity of high angle misorientation may indicate the beginning of recrystallization. Such a complex figure for the texture after cold rolling, as demonstrated in the Figures 12 to 15 , cannot be explained by assuming an in-plane strain state during cold rolling. Uniform in-plane compression gives no explanation for the appearance of cube texture. As we demonstrated in [23], a shear component beside an inplane strain may give a relevant contribution to the 

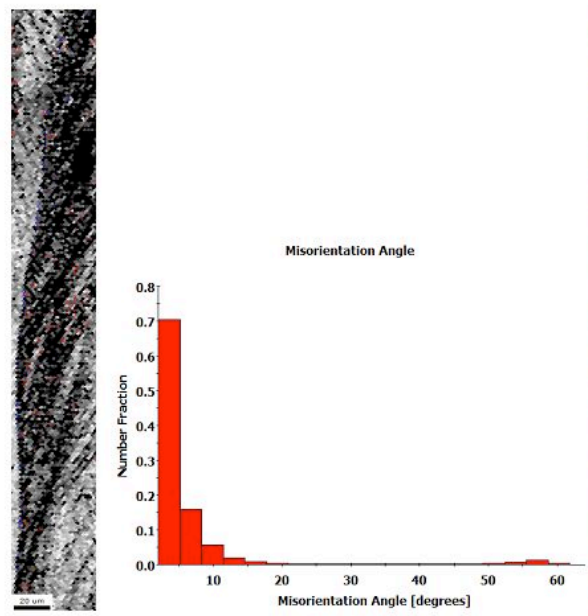

IQ

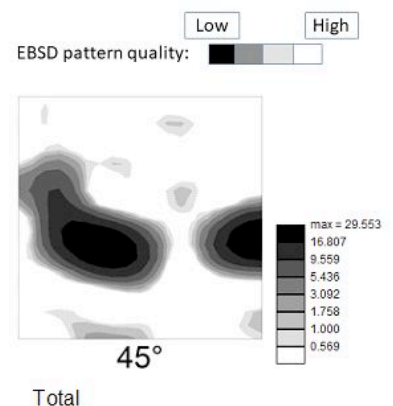

Total

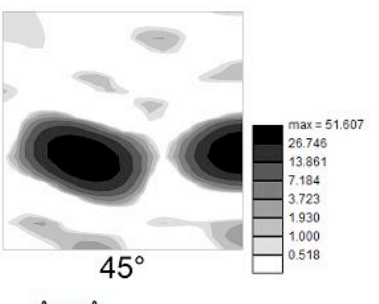

Area A

Figure 13: $I Q$, distribution function of misorientation vs. angle, OIM and $\varphi_{2}=45^{\circ}$ section of the orientation distribution function for a band with mainly $Y$ - fiber texture (selected area of sample 7 (see Figure 11) after cold rolling.
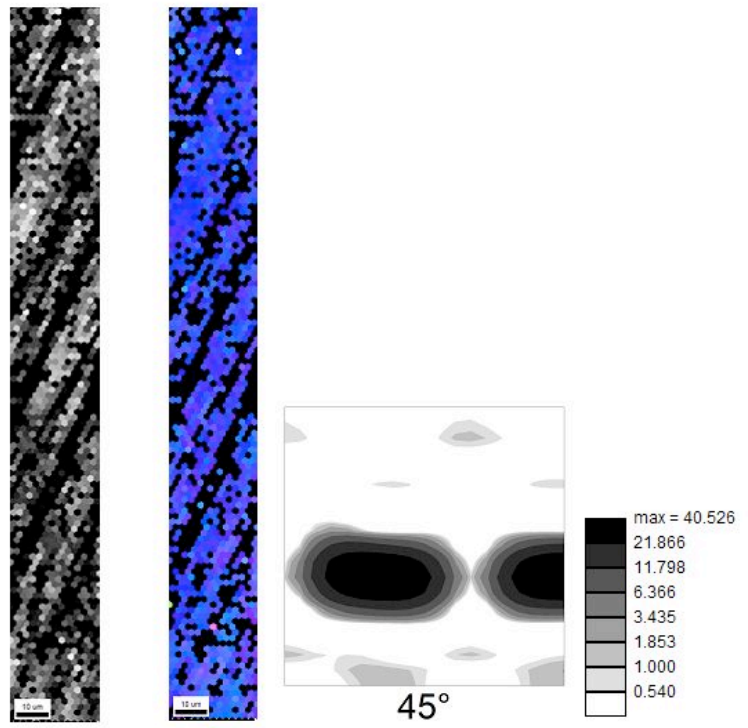

Figure 14: IQ, OIM and the $\varphi_{2}=45^{\circ}$ section of the ODF for an area with $\gamma$ - fiber texture of sample 7 after cold rolling, which contains shear bands.

resulting texture after cold rolling, see also Figure 16. The Figure shows the effect of a shear component to the value of the Taylor factor, which present a measure for the stored energy at cold rolling. The parameter $\mathrm{K}$ characterizes the intensity of a shear stress. As can be seen in Figure 16, the existence of shear stress changes the well-known relation between the stored energy of deformation for various orientations in the case of uniform in-plane strain compression [24] remarkable. Such modified relations between the stored energy of deformation for various orientations may be finally applied to describe the texture in the various areas with different misoriented substructures (deformed states).
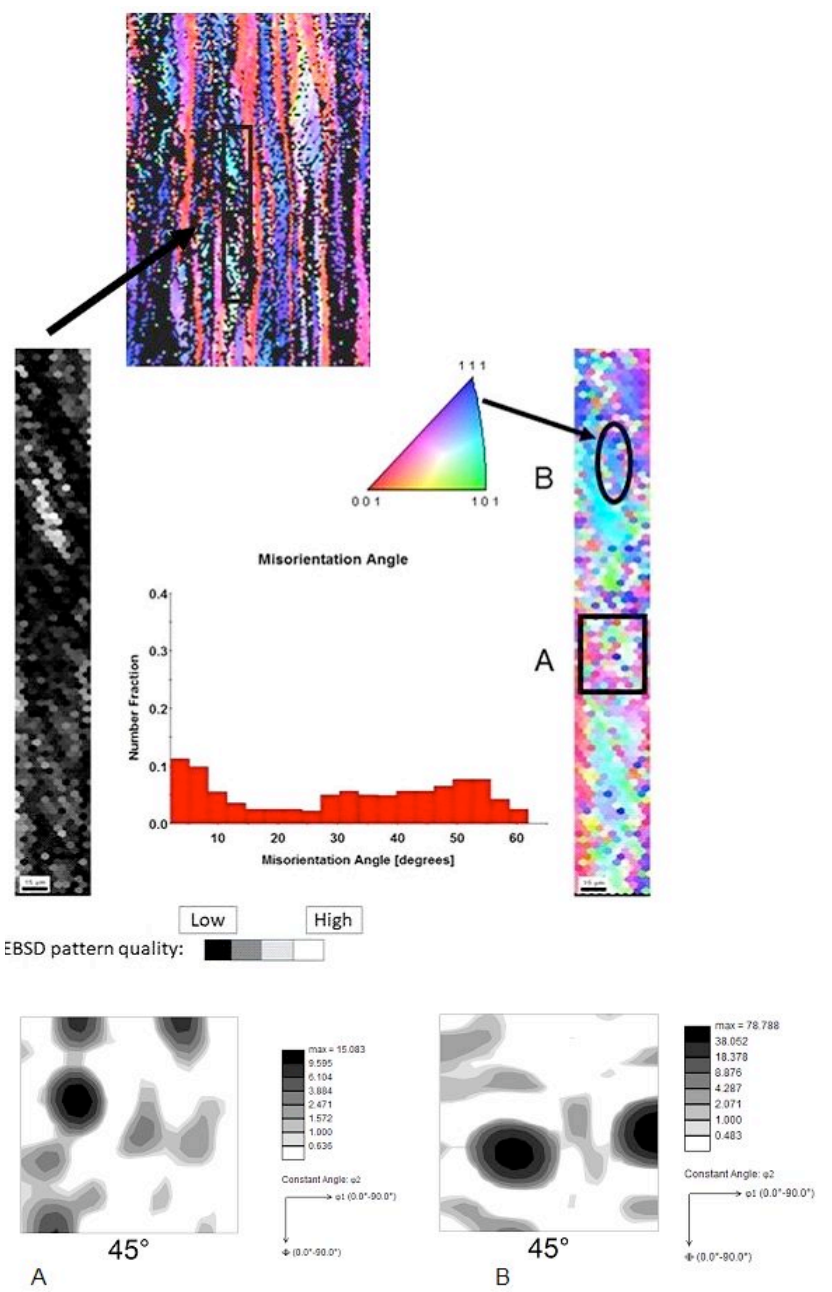

Figure 15: $I Q$, distribution function of misorientation vs. angle, OIM and $\varphi_{2}=45^{\circ}$ section of the orientation distribution function for a transition zone of sample 2 after cold rolling.

\section{CONCLUSIONS}

It is demonstrated that different microstructure of the hot strip before cold rolling results in quite different deformation substructures after cold rolling. Thereby rather different local deformation structures across the thickness are observed. The deformation substructure 


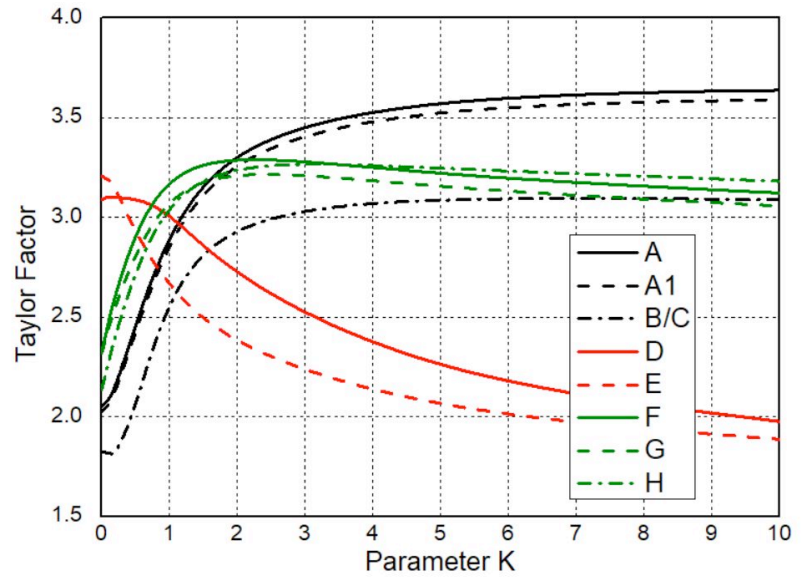

Figure 16: The Taylor factor for different texture components and fibers as function of the parameter $\mathrm{K}$ (for the notation of the texture components and fibers see Figure 1).

after cold rolling depends on the processing conditions at hot band fabrication: finishing temperature, deformation at the last pass, cooling conditions after the last pass, respectively annealing conditions as well as on the process parameters at cold rolling: number of passes, deformation per pass, and temperature at cold rolling. The characteristic of the deformation structure for these ferritic FeSi steels differs remarkable for those of conventional steels. Any modelling of the resulting texture after cold rolling and finally of the recrystallization texture after annealing these cold rolled material has to take into account also a shear stress contribution to the stored deformation energy beside a uniform in-plane strain at cold rolling. The resulting deformation substructures after cold rolling will affect the kinetic of the ongoing processes at final annealing: recovery, recrystallization $[11,15,25]$. A deeper understanding of the interrelations between the microstructure of the hot strip and the deformation energy of the cold rolled material may be a basic for further improvements of the technology and of the final obtained properties.

\section{REFERENCES}

[1] E. Gomes, J. Schneider, K. Verbeken, H. Hermann, Y. Houbaert, Effect of Hot and Cold Rolling on Grain Size and Texture in Fe-Si Strips with Si-Content Larger than 2 wt\%, Mater. Sci. Forum 638-642 (2010), p. 3561.

https://doi.org/10.4028/www.scientific.net/MSF.638-642.3561 K. Verbeken, J. Schneider, J. Verstraete, H. Hermann, Y. Houbaert, Effect of Hot and Cold Rolling on Grain Size and Texture in Fe-2.4wt\%Si Strips, IEEE Trans. on Magn. 44 (2008), p.3820. https://doi.org/10.1109/TMAG.2008.2001318

JT. Park, JA. Szpunar. SY. Cha, Effect of Heating Rate on the Development of Annealing Texture in Nonoriented Electrical Steels, ISIJ Inter. 43 (2003), p.1611. https://doi.org/10.2355/isijinternational.43.1611
[4] JT. Park, JA. Szpunar, Evolution of recrystallization texture in nonoriented electrical steels, Acta Materialia 51 (2003), p.3037. https://doi.org/10.1016/S1359-6454(03)00115-0

[5] JT. Park, JA. Szpunar, Effect of initial grain size on texture evolution and magnetic properties in nonoriented electical steels, J. Magn. Mater. 321(2009) 1928. https://doi.org/10.1016/j.jmmm.2008.12.015

[6] Jurij J. Sidor, K. Verbeken, E. Gomes, J. Schneider, PR. Calvillo, Leo A.I. Kestens. Through Process Texture Evolution and Magnetic Properties of High Si Non-Oriented Electrical Steels, Mater Charact. 71 (2012), p. 49 https://doi.org/10.1016/j.matchar.2012.06.006

[7] O. Fischer, J. Schneider, Influence of Deformation Process on the Improvement of Nonoriented Electrical Steel, J. Magn. Mater. 254-255 (2003), p. 302 https://doi.org/10.1016/S0304-8853(02)00965-4

J. Schneider, K. Verbeken, Y. Houbaert, Texture Evolution During Thermo-Mechanical Processing of High Si electrical Steels - A Comment, Proc. 4. International Conference Magnetism and Metallurgy WMM12, Gent, 20-22 June 2012, p. 367

[9] KM. Lee et al., Effect of texture and grain size on magnetic flux density and core loss in non-oriented electrical steel containing 3.15\% Si, J. Magn. Mater. 354 (2014) 324 https://doi.org/10.1016/.j.jmmm.2013.11.030

[10] S. Paolinelli, Non-oriented Silicon Steels with Improved Texture, Proc. 5. Int. Conf. Magnetism and Metallurgy WMM12, Gent, (2012) 120

[11] J. Schneider, A. Stöcker, A. Franke, C. Schröder. G. Li and $\mathrm{H}$. Hermann, Evolution of Microstructure and Texture Along the Processing Route of Ferritic Nonoriented FeSi Steels, Proc. 6th Int. Conference on Magnetism and Metallurgy WMM14 Cardiff (2014), 208

[12] Hai-Tao LIU, J. Schneider, A. Stöcker, A. Franke, F. Gao, HY. Song, ZY. Liu, R. Kawalla and G.-D. Wang Microstructure and Texture Evolution in Non-oriented Electrical Steels along Novel Strip Casting Route and Conventional Route, steel research int. 87 (2015) 589-598. https://doi.org/10.1002/srin.201500351

[13] J. Schneider, A. Franke, A. Stöcker, HT. Liu, GD. Wang, R Kawalla, Evolution and Interaction of the Microstructure and Texture at the Different Processing Steps for Ferritic Nonoriented Electrical Steels, IEEE Trans. on Magn. 52 (2016) 1-6. https://doi.org/10.1109/TMAG.2016.2530147

[14] W. Saikaly et al., Effect of cold rolling reduction and prior grain size on the final microstructure and magnetic properties of thin gauge low loss fully processed electrical steels, Proc. Conference SMM Sao Paulo 2015.

[15] J. Schneider, A. Stöcker, A. Franke, and R. Kawalla, Effects by the microstructure after hot and cold rolling on the texture and grain size after final annealing of ferritic non-oriented FeSi electrical steel, AIP Advances 8, 047606 (2018). https://doi.org/10.1063/1.4993526

[16] G. Gottstein, Physikalische Grundlagen der Materialkunde Springer Berlin Heidelberg 2007

[17] D. Raabe, Physical Metallurgy, $5^{\text {th }}$ Edition, Elsevier (2014), p. 2291.

https://doi.org/10.1016/B978-0-444-53770-6.00023-X

[18] PR. Calvillo, J. Schneider and Y. Houbaert, Characterization of Flat Rolled High-Silicon Steel by EBSD, Defect and Diffusion Forum Online:2009-03-02 ISSN: 1662-9507, Vols. 283-286, 413.

https://doi.org/10.4028/www.scientific.net/DDF.283-286.413

[19] B. Hutchinson, Deformation Substructures and Recrystallization, Mat. Science. Forum, 668 (2007), 13. https://doi.org/10.4028/0-87849-443-x.13

[20] Jae-Young Choi, Jong-Tae Park, Byung-Keun Bae and Jae- 
Kwan Kim, The Effects of Hot Band Annealing Temperature on the Texture of $1 \%$ and $2 \%$ Si Nonoriented Electrical Steels, Material Science Forum Vols. 558-559 (2007), 701. https://doi.org/10.4028/www.scientific.net/MSF.558-559.701

[21] S. Fortunati, S. Cicalè, Jürgen Schneider, Armin Franke, Rudolf Kawalla, Developments in the Field of Electrical Steels over the Last Years, Proc. 7th International Conf. Magnetism and Metallurgy WMM18, June Rome, Italy (2016), p.29, ISBN 9788890003301

[22] D. Raabe, Overview on Basic Types of Hot Rolling Textures of Steels, steel research 74, No. 5 (2003), 327. https://doi.org/10.1002/srin.200300194
[23] B. Bacroix, J. Schneider, A. Franke, to be published R. K. Ray, JJ. Jonas and RE. Hook, Cold Rolling and annealing textures in low carbon and extra low carbon steels, International Materials Review Vol. 39, No. 4 (1994), 129. https://doi.org/10.1179/imr.1994.39.4.129

[24] RK. Ray, JJ. Jonas and RE. Hook, Cold Rolling and annealing textures in low carbon and extra low carbon steels, International Materials Review Vol. 39, No. 4 (1994), 129

[25] J. Schneider, A. Franke, A. Stöcker and R. Kawalla, Deformation Structure and Recrystallization of Ferritic FeSi Steels, steel research int. 87, no. 8 (2016), p.1054. https://doi.org/10.1002/srin.201500447

Received on 20-12-2018

Accepted on 30-12-2018

Published on 31-12-2018

DOI: https://doi.org/10.31875/2410-4701.2018.05.5

(C) 2018 Franke et al.; Zeal Press.

This is an open access article licensed under the terms of the Creative Commons Attribution Non-Commercial License (http://creativecommons.org/licenses/by-nc/3.0/) which permits unrestricted, non-commercial use, distribution and reproduction in any medium, provided the work is properly cited. 